\title{
Noradrenergic Hyperinnervation of the Motor Trigeminal Nucleus: Alterations in Membrane Properties and Responses to Synaptic Input
}

\author{
James J. Vornov and Jerome Sutin \\ Department of Anatomy and Cell Biology, Emory University School of Medicine, Atlanta, Georgia 30322
}

The physiological consequences of the noradrenergic (NE) hyperinnervation of the rat brain stem produced by neonatal administration of 6-hydroxydopamine (6-OHDA) was studied in the motor trigeminal nucleus. Stimulation of the region of the lateral lemniscus, the source of the noradrenergic innervation of the nucleus, facilitated the masseteric reflex for up to 200 msec in both normal and hyperinnervated animals. The peak facilitation was $71 \%$ larger in the $\mathrm{NE}$ hyperinnervated animals and was reduced by systemically administered alpha- and betaadrenergic receptor antagonists.

Intracellular recordings revealed that the mean resting potential of NE hyperinnervated trigeminal motoneurons was $3 \mathrm{mV}$ more hyperpolarized than that of normal cells. The mean input resistance of $\mathrm{NE}$ hyperinnervated motoneurons was reduced from $1.83 \pm 0.15$ to $1.22 \pm 0.19 \mathrm{M} \Omega$. NE hyperinnervation increased the amplitude of the monosynaptic EPSP evoked by stimulation of primary afferent cell bodies in the mesencephalic trigeminal nucleus (MesV) by 65\%. The mean rise time of the EPSP was increased in NE hyperinnervated motoneurons while the mean half-width was unchanged, suggesting a shift in the distribution of primary afferent terminals away from the motoneuron soma.

Stimulation of the lateral lemniscus region produced a predominantly depolarizing PSP with a time course similar to that of the reflex facilitation. The amplitude of the depolarization in NE hyperinnervated motoneurons was not significantly different from that of controls. During this lateral lemniscus regionevoked PSP, stimulation of MesV produced an EPSP of increased amplitude, associated with a decrease or no change in input resistance. These observations support the hypothesis that increasing the density of noradrenergic terminals in the motor nucleus increases facilitation of the masseteric reflex, which is associated with the increase in the amplitude of the intracellularly recorded MesV-evoked monosynaptic EPSP in trigeminal motoneurons.

In the rat, neonatal administration of the neurotoxin, 6-hydroxydopamine (6-OHDA) produces permanent changes in the distribution of CNS terminals containing norepinephrine (NE). The forebrain and spinal cord are largely depleted of NE, while the NE content of the cerebellum and some brain stem areas is increased (Jonsson et al., 1974; Levitt and Moore, 1980; Sachs et al., 1974). In particular, the NE content of the motor trigeminal nucleus is increased several-fold (Levitt and Moore, 1980).

\footnotetext{
Received June 18, 1984; revised June 11, 1985; accepted June 11, 1985.

This work was supported by NIH Grant NS-14778, NIH Medical Scientist Training Program Grant GM-07415, the Helen Miller Endowment Award to Emory University School of Medicine, and a grant from the United Cerebral Palsy Foundation.

Correspondence should be addressed to Dr. Jerome Sutin, Department of Anatomy and Cell Biology, Emory University, Atlanta, GA 30322.

Copyright (C) 1986 Society for Neuroscience $0270-6474 / 86 / 010030-08 \$ 02.00 / 0$
}

The motor trigeminal nucleus consists almost entirely of the motoneurons innervating the muscles of mastication and contains few interneurons within its borders (Sessle, 1977). The anatomy of the brain stem projections to the normal and noradrenergically hyperinnervated motor trigeminal nucleus has been described (Vornov and Sutin, 1983a). The NE innervation of the nucleus arises exclusively from an ipsilateral group of neurons scattered among the fibers of the lateral lemniscus (LL region). In animals treated neonatally with 6-OHDA, the increased innervation originates from the same NE cell group normally innervating the nucleus, maintaining the anatomical specificity of the projection.

While this anatomically observed increase in the number of transmitter release sites could amplify the normal synaptic response, compensatory changes in postsynaptic sensitivity to monoamines also occur (Reisine, 1981; Schwartz et al., 1978). For example, NE denervation of the cerebral cortex (Sporn et al., 1976, 1977) or cerebellum (Wolfe et al., 1982) increases the density of specific populations of adrenergic receptors and increases the sensitivity of adenyl cyclase activity to catecholamine stimulation (Kalisker et al., 1973; Sporn et al., 1976). Chronic administration of tricyclic antidepressants decreases the sensitivity of adenylate cyclase to catecholamines (Frazer et al., 1978) and decreases beta-adrenergic binding (Rosenblatt et al., 1979; Wolfe et al., 1978), presumably by increasing the concentration of norepinephrine at the postsynaptic receptor through inhibition of presynaptic reuptake. The NE hyperinnervation of the cerebellum produced by neonatal 6-OHDA has been reported to reduce the density of beta-adrenergic receptors (Harden et al., 1979; Jonsson and Hallman, 1978). An electrophysiologically defined denervation supersensitivity to iontophoretically applied norepinephrine has been described in the cerebellum (Hoffer et al., 1971). Similarly, neurons of the facial nucleus (McCall and Aghajanian, 1979) and amygdala (Wang et al., 1978) develop a supersensitivity to iontophoretic serotonin following destruction of their serotonergic innervation.

Despite the well-established ability of NE axons to sprout in response to CNS injury or other experimental manipulations, there have been no previous attempts to test the hypothesis that an increased innervation density produces a change in excitability or synaptic efficacy. In the current series of experiments, $\mathrm{NE}$ actions on trigeminal motoneuron excitability in normal and NE hyperinnervated animals were examined by measuring the conditioning effects of stimulation of the LL region on the amplitude of the masseteric reflex (Bonvallet and Bobo, 1975; Kidokoro et al., 1968; Sauerland et al., 1967). Intracellular recordings from trigeminal motoneurons were made in order to investigate the action of NE hyperinnervation upon the membrane properties of trigeminal motoneurons and their response to the non-noradrenergic monosynaptic input from primary afferents. This work has been reported previously in abstract form (Vornov and Sutin, 1983b, c). 


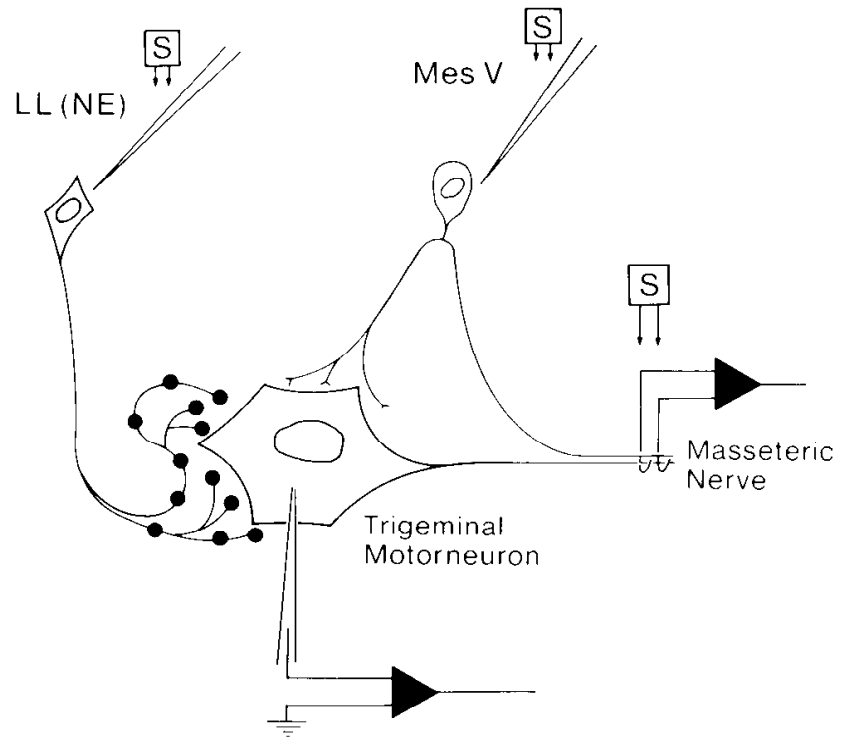

Figure 1. Schematic of the neuronal circuit involved in studying NE hyperinnervation effects. The masseteric reflex is recorded with bipolar hook electrodes as a compound action potential in the masseteric nerve following stimulation ( $S$ ) of the mesencephalic trigeminal nucleus (MesV). The stimulus to MesV can be preceded by a conditioning stimulus to noradrenergic $(N E)$ neurons in the region of the lateral lemniscus $(L L)$ in order to examine the effects of its activation on motoneuron excitability. When trigeminal motoneurons are recorded intracellularly, the masseteric nerve electrode is used to activate motoneurons antidromically and MesV is stimulated for orthodromic activation.

\section{Materials and Methods}

Adult Sprague-Dawley rats, ranging in weight from 200 to $400 \mathrm{gm}$, were used in all experiments. One group of 20 rats received subcutaneous injections of $100 \mathrm{mg} / \mathrm{kg} 6-\mathrm{OHDA}$ in $1 \%$ ascorbic acid and $0.85 \% \mathrm{NaCl}$ on postnatal days 1 and 2 . Thirty uninjected littermates served as controls. For recording experiments, rats were anesthetized with $30 \mathrm{~cm}^{3} /$ $\mathrm{kg}$ i.p. of a saturated solution of alpha-chloralose. The trachea and, in some cases, the femoral artery and vein were cannulated. The animal was placed in a stereotaxic frame, the skull and dura over the occipital cortex removed, and the exposed cortex covered with 3\% agar in Ringer's solution to prevent drying. The masseteric nerve was exposed by reflecting the temporalis muscle away from the skull and removing the posterior portion of the zygomatic arch. The nerve was ligated, cut distally, and placed on bipolar hook electrodes for recording compound action potentials. The nerve and recording electrodes were covered with a paraffin/paraffin oil mixture to prevent drying. Core temperature was maintained near $37^{\circ} \mathrm{C}$ by means of an electric heating pad. Before recording, the animal was immobilized with $50 \mathrm{mg}$ i.p. gallamine triethiodide and mechanically ventilated. In an initial group of animals, endtidal $\mathrm{CO}_{2}$ was monitored, using an IR analyzer (Beckman LB-1). We found that the parameters of pump volume and rate necessary to maintain $\mathrm{CO}_{2}$ between 5 and $5.5 \%$ were quite constant from animal to animal, and we therefore did not continue monitoring in subsequent experiments.

The neural circuit producing the masseteric reflex is shown schematically in Figure 1. Using the atlas of Pelligrino et al. (1967), a monopolar stimulating electrode was placed in the MesV to evoke a monosynaptic response from trigeminal motoneurons, recorded as a compound action potential in the masseteric nerve. In some animals, electrode placement was medial and ventral to the cells of MesV in the tract of Probst, which contains the central processes of the primary afferents (Astrom, 1953; Matesz, 1981).

A second monopolar stimulating electrode was placed in the region of the LL region, which contains the NE neurons that project to the motor trigeminal nucleus (Vornov and Sutin, 1983a). An ISAAC/Apple II microcomputer system was used to generate conditioning curves. The computer triggered the conditioning lateral lemniscus stimulus and, following selected intervals, triggered the test MesV stimulus. The masseteric nerve response was digitized and peak amplitude measured. The intertrial interval between presentation of the paired stimuli was 10 sec.
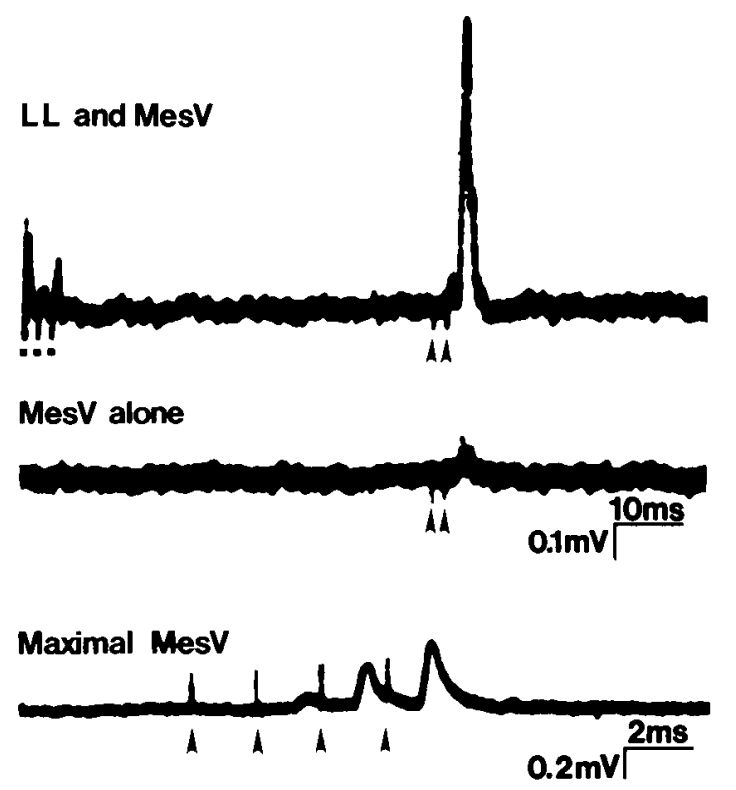

Figure 2. Facilitation of the masseteric reflex. In the middle record, MesV was stimulated (arrows, two stimuli, $500 \mathrm{~Hz}$ ), evoking the small response recorded in the nerve. When the same stimulus was preceded by a train of three stimuli at $1000 \mathrm{~Hz}$ (squares, upper record) to the region of the lateral lemniscus $(L L)$, the reflex evoked by the MesV stimulus was greatly increased. The proximity of the NE neurons to the motor trigeminal nucleus and the exit of the trigeminal motor root from the brain stem sometimes led to stimulus spread to these structures, resulting in the $1 \mathrm{msec}$ latency responses seen following the $L L$ region stimulus artifacts. In the bottom record, MesV alone is stimulated repetitively $(500 \mathrm{~Hz}$, arrows) to produce a maximal reflex response used for normalizing responses.

The conditioning stimulus to the $\mathrm{LL}$ region consisted of a train of three stimuli at either 500 or $1000 \mathrm{~Hz}$ and $0.01 \mathrm{msec}$ pulse duration, set at the lowest current (less than $45 \mu \mathrm{A}$ ) that would produce a maximal facilitation of the masseteric reflex at a condition-test interval of 35 or $40 \mathrm{msec}$. The test stimulus to MesV consisted of two pulses of less than $30 \mu \mathrm{A}$ at either 500 or $1000 \mathrm{~Hz}$ at $0.01 \mathrm{msec}$ pulse duration, with the intensity set to evoke a small, but constant, reflex response in the absence of the conditioning stimulus (Fig. 2, middle trace). A series of 50 trials of the MesV test stimulation alone was digitized and averaged. The maximal masseter nerve response that could be produced by MesV stimulation alone at a given stimulus intensity was determined by incrcasing to six the number of stimuli in the train (Fig. 2, bottom trace); this response was considered to be the activity of the entire pool of motoneurons that could be discharged by the MesV stimulus. The difference between the maximal response and the test response (Max Test) was the range over which facilitation could occur. The amplitude of the masseteric reflex evoked during three trials at each conditioning interval was averaged to obtain the conditioned reflex amplitude (Cond). The test stimulus amplitude was subtracted to measure the increase in reflex amplitude at each interval (Cond - Test). The fraction of maximal facilitation was calculated according to the formula,

$$
\text { Normalized facilitation }=\frac{(\text { Cond }- \text { Test })}{(\text { Max }- \text { Test })}
$$

After the reflex responses were characterized, intracellular recordings were made (see below), or the effects of intraperitoneally administered adrenergic blocking agents tested. The nonselective beta-adrenergic receptor antagonist, propranolol, was given in doses of $10 \mathrm{mg} / \mathrm{kg}$ and caused little or no change in the animal's heart rate or blood pressure. The nonselective alpha-adrenergic receptor antagonist, phentolamine ( $2 \mathrm{mg} / \mathrm{kg}$ ), caused a drop in blood pressure of less than $15 \mathrm{mmHg}$ and a reflex tachycardia. A major concern was possible nonspecific effects on neuronal excitability due to the systemic cardiovascular effects of the drugs; however, in the six animals receiving blocking drugs there were no decreases in the maximal MesV response and no increases in MesV thresholds. At the conclusion of each experiment, a positive DC 


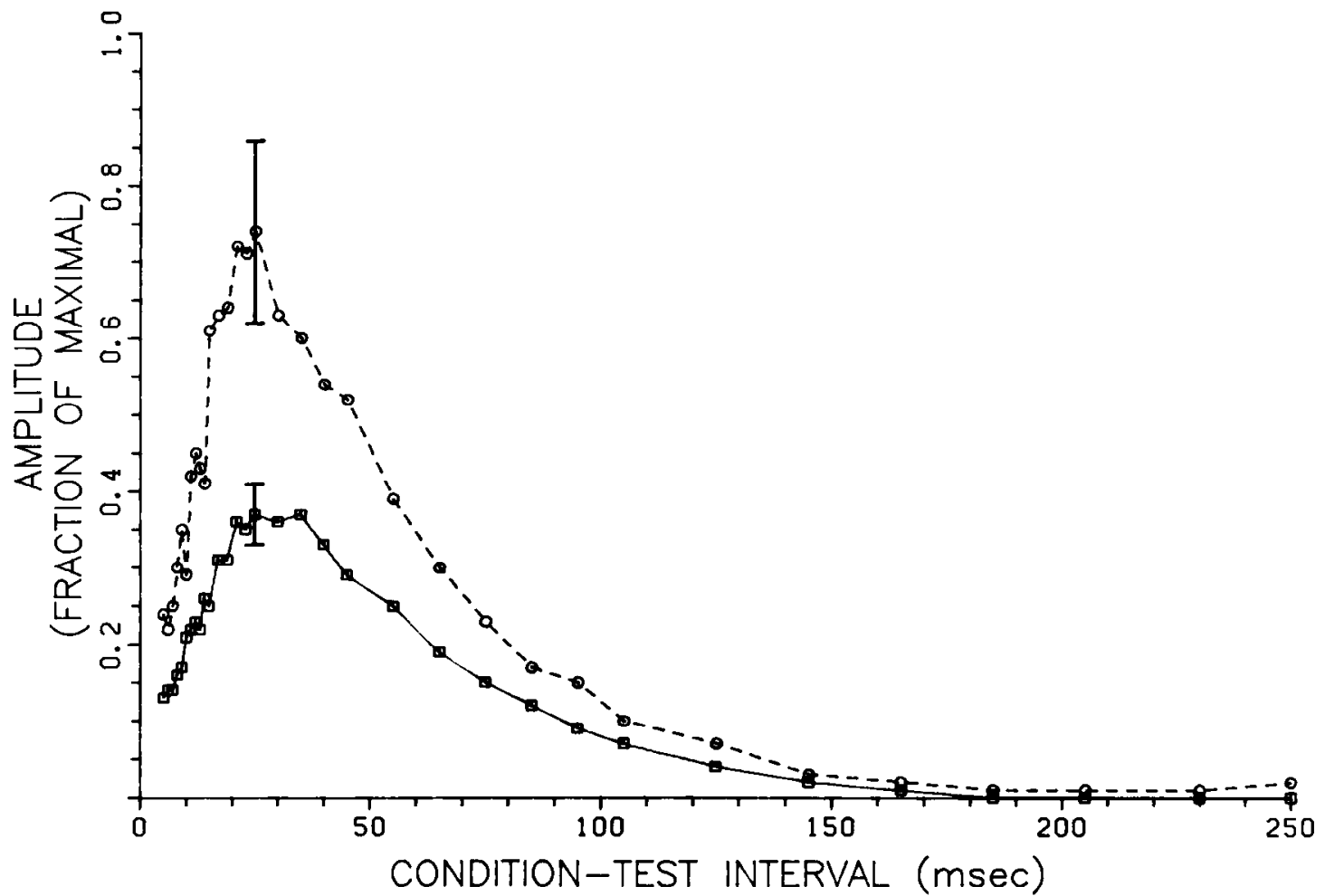

Figure 3. Conditioning curves from normal $(\square)$ and neonatal 6-OHDA-treated $(O)$ animals. Averages of individual conditioning curves are plotted for 18 normal and 7 neonatal 6-OHDA-treated rats. SEM is shown for the 20 msec condition-test interval, for illustrative purposes. The mean peak facilitation in the normal animals was $0.48 \pm 0.05$ (mean \pm SEM) at a mean condition-test interval of $19.7 \pm 1.4 \mathrm{msec}$. Peak facilitation in the neonatal 6-OHDA-treated animals was $0.82 \pm 0.13$ at a mean condition-test interval of $21.3 \pm 1.5 \mathrm{msec}$.
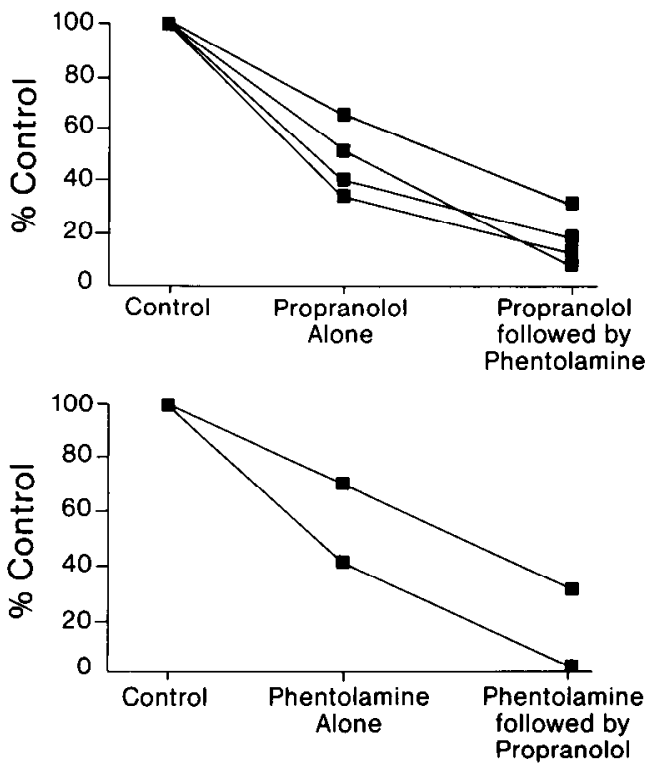

Figure 4. Effects of systemic administration of adrenergic receptor antagonists on peak facilitation of the masseteric reflex. Facilitation following phentolamine $(2 \mathrm{mg} / \mathrm{kg})$ and propranolol $(10 \mathrm{mg} / \mathrm{kg})$ administration are expressed as percentages of the maximal facilitation observed before drug administration. Each point represents the average of nine measurements in one animal at the same condition-test interval that produced the maximum pre-drug facilitation. Drugs were administered successively in the order indicated; measurements were made 30,45 , and 90 min after injection of each drug, and averaged. The second drug was administered 120 min after the first. current of $0.5 \mathrm{~mA}$ was passed through each electrode for $20 \mathrm{sec}$ to aid in subsequent histological identification of the stimulation sites.

Micropipettes filled with $2 \mathrm{M}$ potassium citrate, with tip diameters $<1.5 \mu \mathrm{M}$ and impedances of 4-20 M , were employed with a highimpedance, unity gain amplifier with capacitance neutralization. The electrode formed one arm of a bridge circuit that allowed intracellular injection of current (Araki and Otani, 1955). A test pulse was periodically passed through the electrode to monitor electrode impedance and capacitance. The output of the amplifier was displayed directly on an $x-y$ plotter for a continuous record of resting membrane potential, and was also amplified and displayed on a storage oscilloscope.

The recording electrode was directed stereotaxically to the trigeminal motor nucleus, which was identified by the presence of a large negative field potential evoked by MesV or masseteric nerve stimulation (Chase et al., 1980; Desantis et al., 1978). The recording position was confirmed by subsequent histological examination of the electrode tracks. Only intracellular impalements giving a stable membrane potential greater than $50 \mathrm{mV}$ for periods ranging from $15 \mathrm{~min}$ to $2 \frac{1 / 2}{\mathrm{hr}}$ are included in the data analysis. The resting potential was measured periodically during the impalement and an average calculated. Input impedance was measured by the bridge imbalance method (Araki and Otani, 1955; Frank and Fuortes, 1956). In most cases, the bridge was balanced outside of the cell and then, following impalement, the voltage offset produced by a $10 \mathrm{msec}, 1.2 \mathrm{nA}$ microelectrode negative square wave was measured.

The ISAAC/Apple system was used to digitize and average intracellular recordings (118 $\mu \mathrm{sec} / \mathrm{sample})$. Signals were analyzed on line and/ or recorded with an FM tape recorder for later analysis. Synaptically evoked potentials were averaged over 15-100 trials and the latency, amplitude, rise time, and half-width calculated using a modified version of a waveform analysis program written by Teyler et al. (1982).

\section{Results}

Facilitation of the masseteric reflex by stimulation of the $L L$ region

The $L L$ region contains the NE neurons that project to the motor trigeminal nucleus (Vornov and Sutin, 1983a). Stimulation of 
A
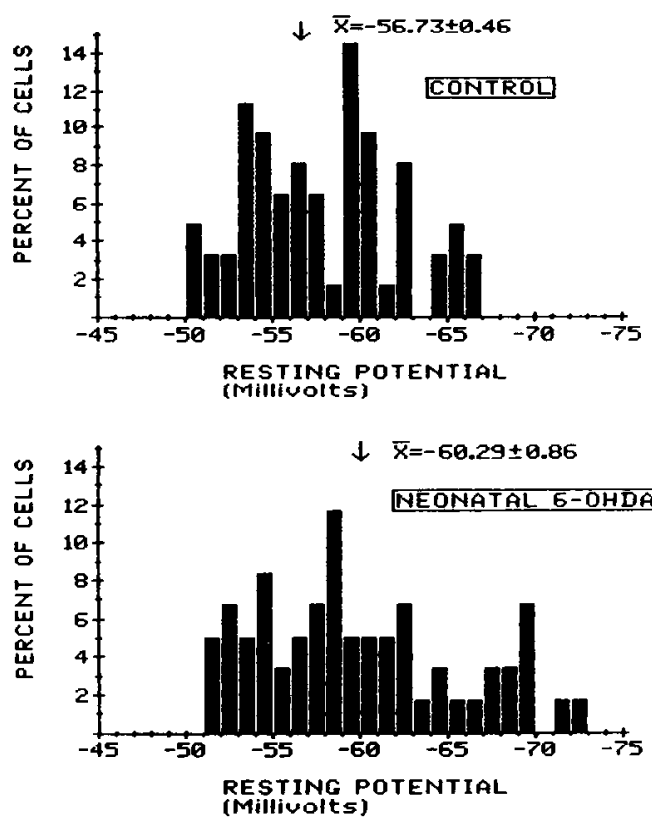

B
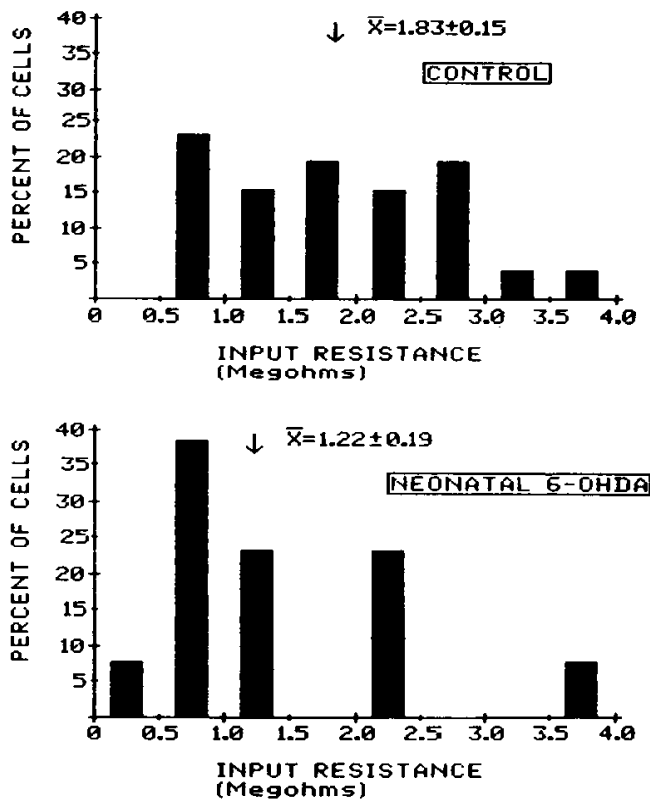

Figure 5. Distributions of resting potential and input resistance in trigeminal motoneurons. $A$, Percentage of cells at each mean resting potential in normal (upper histogram) and neonatal 6-OHDA-treated (lower histogram) rats. B, Distribution of input resistances. Data are grouped into 0.5 $\mathrm{M} \Omega$ bins. The mean (arrows) and the SEM are indicated for each plot.

this area strongly facilitated the masseteric reflex, as illustrated in Figure 2. Peak facilitation occurred at a mean condition-test interval of $23 \mathrm{msec}$, and the facilitation always lasted at least $100 \mathrm{msec}$. Maximal facilitation required an intertrial interval of at least $5 \mathrm{sec}$. LL region conditioning stimuli alone produced no synchronized discharge of motoneurons (Fig. 2, top trace).

A series of 18 normal and 7 neonatal 6-OHDA-treated rats were compared to test the hypothesis that an increased density of NE innervation leads to increased facilitation (Fig. 3). The peak facilitation in the neonatal 6-OHDA-treated group was $71 \%$ greater than in the control group ( $p<0.005$; Student's $t$ test), and the area under the conditioning curve was increased by $78 \%(p<0.01)$. The time course of the facilitation was unchanged. The sizes of the motoneuron pools studied in the two groups were similar, since the maximal responses to MesV stimulation alone (Max) did not differ significantly $(p>0.05)$. Similarly, the amplitudes of the unconditioned response (Test) were not significantly different $(p>0.05)$.

Stimulation of the LL region may also activate non-noradrenergic cells or axons that project directly or polysynaptically to the motor trigeminal nucleus. For this reason, drugs known to block adrenergic receptors were administered systemically to confirm that the facilitation we observed was mediated by adrenergic receptors. Drugs were administered successively: Four rats received propranolol first, which was followed $2 \mathrm{hr}$ later by phentolamine. Two rats received the drugs in the opposite order. The data from these experiments are illustrated in Figure 4; the combination of propranolol and phentolamine, administered in either order, significantly reduced the facilitation $(p<0.001$; paired $t$ test). However, neither agent alone completely blocked the facilitation.

Phentolamine, alone or following propranolol administration, caused an increase in the response to MesV test stimulation alone. In order to maintain a consistent method of data collection, the MesV stimulus intensity was decreased until an amplitude typical of the resting response was evoked. This decreased intensity was still capable of eliciting the predrug maximal response when the stimulus train was lengthened.
Resting membrane properties and synaptic responses of normal and noradrenergically hyperinnervated motoneurons Intracellular recordings were obtained from a total of 80 trigeminal motoneurons in normal rats and 57 motoneurons in neonatal 6-OHDA-treated rats. Membrane potential and input resistance were compared in the normal and hyperinnervated populations to test whether noradrenergic hyperinnervation alters the resting membrane properties of these neurons. The mean resting potential of 80 trigeminal motoneurons in rats treated neonatally with 6 -OHDA was $-60.29 \pm 0.86 \mathrm{mV}$, which was $3.56 \mathrm{mV}$ more hyperpolarized than the $-56.7 \pm 0.45 \mathrm{mV}$ average of 57 motoneurons recorded in normal animals $(p<0.001)$. As is shown in Figure $5 A$, the distributions of membrane potentials in the two groups overlap extensively, but there are many more NE hyperinnervated cells with resting potentials greater than $-65 \mathrm{mV}$. The mean input resistance of hyperinnervated motoneurons was $33 \%$ lower than in normally innervated cells $(p<0.02)$. Figure $5 B$ illustrates the shift in the distribution of input resistances in the hyperinnervated motoneurons.

There was a $65 \%$ increase in the mean amplitude of the EPSP in recordings from neonatal 6-OHDA-treated animals, compared with controls $(p<0.001)$. The decrease in input resistance measured in hyperinnervated neurons would be expected to decrease EPSP amplitude (Katz and Thesleff, 1957; Kuno and Miyahara, 1969), while the membrane hyperpolarization observed would tend to increase EPSP amplitude. However, the small change in resting membrane potential is insufficient to explain the large increase in EPSP amplitude if the reversal potential of the EPSP is near $0 \mathrm{mV}$ and the synaptic channels are not extremely voltage-sensitive.

EPSP rise times and half-widths were characterized in order to examine possible changes in the distribution of MesV terminals over the motoneuron surface in hyperinnervated animals. There was a significant increase in the rise time as measured from the foot of the EPSP to its peak $(p<0.05)$. The half-widths (widths at half-amplitude) and durations of EPSPs in the hy- 
A
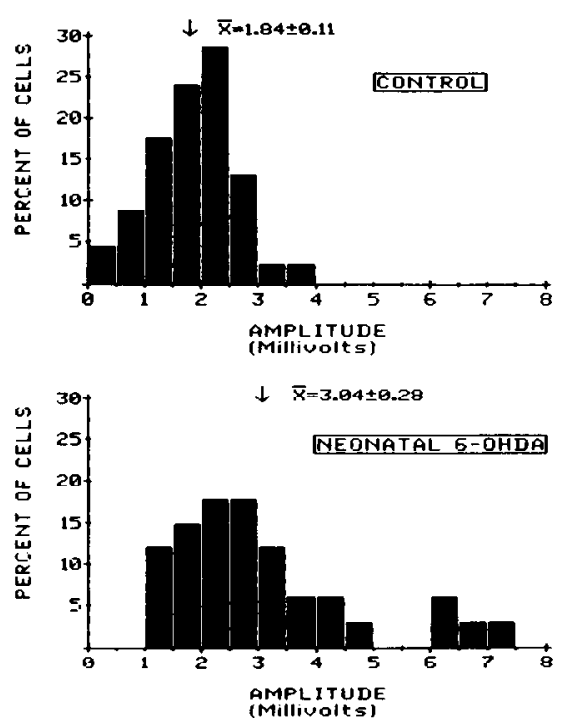

B
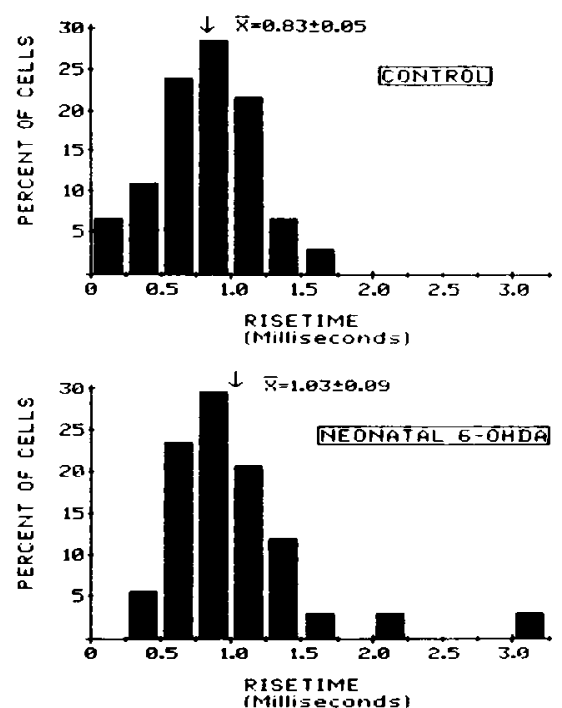

C
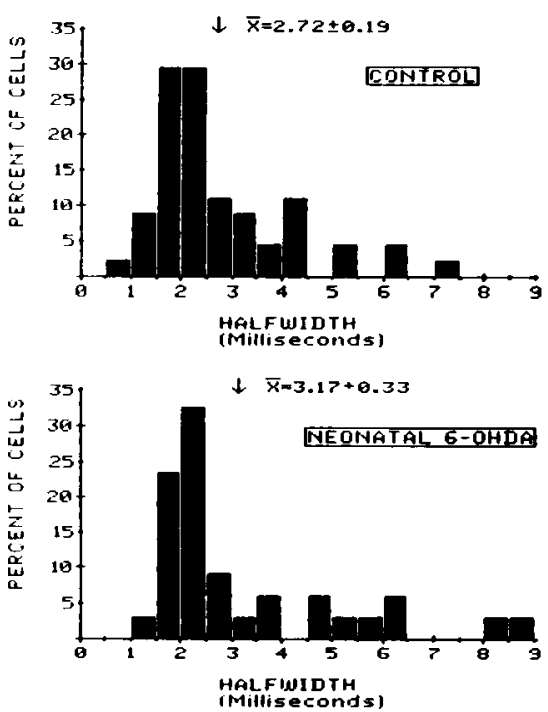

Figure 6. Distributions of MesV-evoked EPSP parameters in trigeminal motoneurons. The distributions of $(A)$ amplitudes (grouped in $0.5 \mathrm{mV}$ bins), $(B)$ rise times (in $0.25 \mathrm{msec}$ bins), and $(C)$ half-widths (in $0.5 \mathrm{msec}$ bins) are illustrated as percentages in control (upper histograms) and NE hyperinnervated motoneurons (lower histograms). The means and SEMs are shown for each histogram.

perinnervated neurons were not statistically different from neurons in control animals. The distributions of rise times and halfwidths for control and neonatally treated animals are illustrated in Figure 6.

\section{LL region-evoked PSPs and facilitation of the monosynaptic EPSP}

The period of $L L$ region-evoked facilitation of the masseteric reflex was correlated with an intracellularly recorded depolarization. PSPs evoked by stimulation were digitized and averaged in 13 cells in normal animals and 18 cells in neonatal 6-OHDAtreated animals. The duration of these PSPs ranged from 75 to $250 \mathrm{msec}$ and often had a complex shape. The PSPs were predominantly depolarizing, but some cells also displayed a hyperpolarizing component (Fig. 7). In most cases, the amplitudes of all components increased or decreased equally as the stimulation intensity was varied. The shape of the PSP did not vary systematically with stimulating clectrode position and, as illustrated in Figure 7, the same electrode position, which was unchanged in each animal, produced a variety of PSP shapes in different cells.

The largest depolarizing amplitude of each $L L$ region-evoked PSP was considered to be the peak amplitude of the response.
No significant difference in amplitude was found between the normal (5.22 $\pm 0.67 \mathrm{mV}$; SEM) and noradrenergically hyperinnervated (4.69 $\pm 0.43 \mathrm{mV}$; SEM) cells.

During the LL region-evoked PSP, the MesV EPSP was increased in amplitude in 10 of 14 consecutively recorded motoneurons in three animals (Fig. $8, A-C$ ). The time course of the EPSP facilitation was similar to that of the LL region-evoked depolarization. During intracellular current injection $(1.2 \mathrm{nA}$, $10 \mathrm{msec}$ ) in 7 of these 10 motoneurons, no change in membrane resistance could be detected (Fig. $8 D$ ) at the same latency at which the MesV EPSP amplitude was increased (Fig. 8A). In three cells, a small bridge imbalance, indicative of a decrease in membrane resistance, was observed. An alternative method of demonstrating changes in input resistance is the measurement of antidromic spike amplitude (Frank and Fuortes, 1956; Llinas, 1964). A decrease in the amplitude of antidromically evoked spikes is evident in recording from the masseteric motoneuron shown in Figure $8 E$, suggesting a conductance increase. However, the change in spike amplitude could also be caused by an effect on the voltage-sensitive channels mediating the action potential (e.g., decreases in $\mathrm{Na}^{+}$or $\mathrm{Ca}^{2+}$ channel activation). There was, however, no evidence that the increased amplitude of the MesV EPSP seen during the PSP evoked by stimulation of the $\mathrm{LL}$ region was due to an increase in membrane resistance.
Figure 7. Examples of LL regionevoked PSPs. Tracings of averaged digitized PSPs evoked by stimulation of the region of the lateral lemniscus, recorded from normal and hyperinnervated trigeminal motoneurons, are illustrated. The LL region was stimulated with a train of three stimuli at $500 \mathrm{~Hz}$. The number preceding each trace is the animal number and, following a decimal point, the cell number from that animal. During recordings from each animal, stimulation sites and parameters were unchanged.
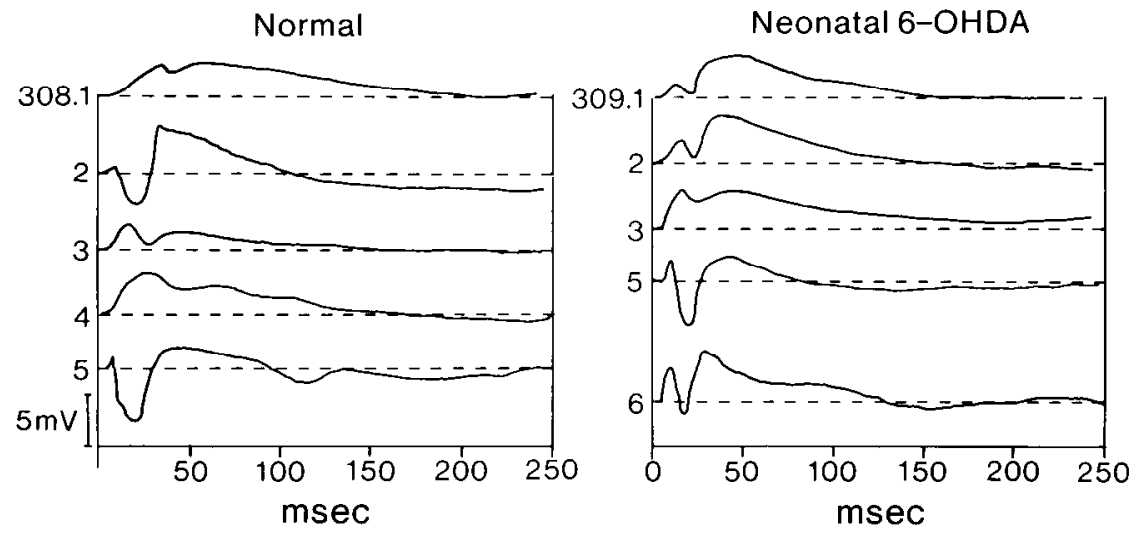

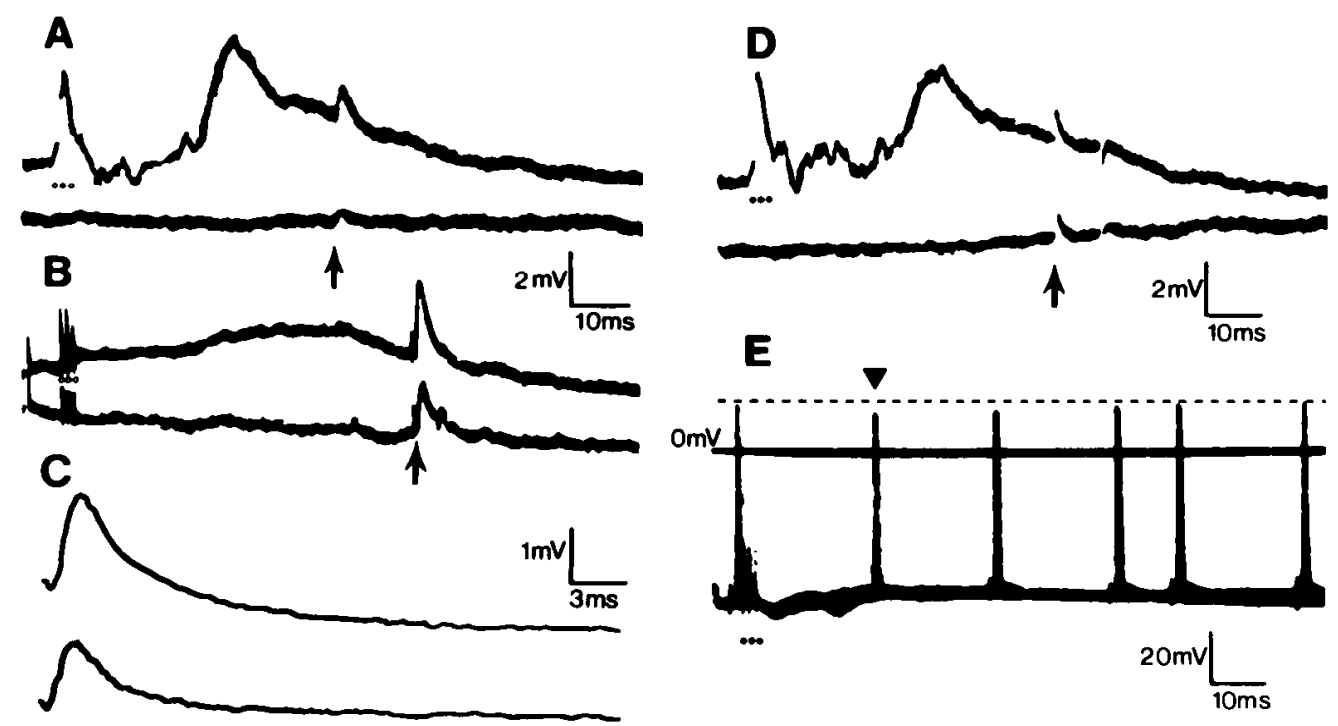

Figure 8. $A$ and $B$, Two examples of the effect of LL region-conditioning stimulation on the intracellularly recorded MesV-evoked EPSP. The EPSP (arrows) had a larger amplitude when preceded by a conditioning stimulus to the lateral lemniscus (three circles, upper traces) than when MesV was stimulated alone (arrows, lower traces). C, Sample digitized MesV-evoked EPSPs, alone (lower record) or preceded by LL region stimulus (upper record). $D$. Intracellular current injection through the balanced bridge alone (lower record, arrow) or preceded by LL region stimuli (three circles, upper record). Same cell as in $A$, at approximately the same latency. No change in input resistance during the LL PSP is apparent. $E$, Antidromic spikes evoked during the LL region-evoked PSP, with six sweeps superimposed. The first spike precedes the LL stimuli (three circles) and the dotted line indicates its amplitude. Antidromic spikes evoked during the PSP have a decreased amplitude (e.g., at arrow), indicating a decrease in input resistance.

\section{Discussion}

Stimulation of the anatomically defined origin of the NE innervation of the trigeminal motor nucleus produced a facilitation of the masseteric reflex, which was increased after neonatal 6-OHDA treatment. The small changes in average membrane potential and input resistance in the postsynaptic cells do not account for the marked facilitation of the reflex observed in NE hyperinnervated animals. While the lowest threshold stimulation sites were within the LL region containing NE neurons of the A7 group (Dahlstrom and Fuxe, 1964), which innervate both the normal and noradrenergically hyperinnervated nucleus (Vornov and Sutin, 1983a), our results must be interpreted with caution since direct evidence of NE mediation of the facilitation is lacking. Systemically administered alpha- and beta-adrenergic receptor antagonists decreased the facilitation, but remote NE effects that indirectly affect the excitability of trigeminal motoneurons cannot be excluded.

In the lumbar spinal cord, stimulation of the descending NE projection from the nucleus locus coeruleus (LC) facilitates the monosynaptic responsc of motoneurons to dorsal root stimulation (Strahlendorf et al., 1980). This action is partially blocked by systemic alpha-receptor antagonists. Peak LC-evoked facilitation occurs at about $40 \mathrm{msec}$ after onset and lasts about 100 msec-a time course comparable to the facilitation described here. This spinal motoneuron facilitation is associated with a membrane depolarization that is partially blocked by alpha antagonists (Fung and Barnes, 1981).

NE iontophoresis onto both spinal (White and Neumann, 1983) and facial (VanderMalen and Aghajanian, 1980) motoneurons also produces a membrane depolarization blocked by alpha-adrenergic antagonists. In locus coeruleus-spinal cord cocultures, Pun et al. (1985) observed an alpha-adrenergic-mediated depolarization following NE iontophoresis or stimulation of the LC. The depolarization was sometimes preceded by a hyperpolarization similar to the biphasic responses we observed.

In both the facial nucleus (VanderMalen and Aghajanian, 1980 ) and in tissue culture (Pun et al., 1985) NE-mediated de- polarization is accompanied by decreased membrane conductance, most likely of potassium ions. We did not observe decreases in membrane conductance during the $L I$ region-evoked PSP. In hippocampal slice preparations, NE, acting on betareceptors, blocks the calcium-activated potassium conductance and increases responses to depolarizing current pulses without changing membrane potential or resistance (Madison and Nicoll, 1982). However, this mechanism prolongs the duration of spike discharges by reducing accommodation and cannot explain increases in the amplitude of the synaptic response of the type observed in our experiments. Since NE augments GABAmediated inhibition in both cerebellum (Moises et al., 1979) and somatosensory cortex (Waterhouse et al., 1980), additional mechanisms must exist by which NE modulates postsynaptic sensitivity to other transmitters (Woodward et al., 1979). Noradrenergic presynaptic increases in the quantity or duration of transmitter release from MesV axon terminals are also consistent with a lack of motoneuron membrane conductance changes.

Neonatal 6-OHDA treatment increased the $L L$ region-evoked facilitation of the masseteric reflex and the MesV monosynaptic EPSP amplitude. Since the amplitude of the depolarization produced by LL stimulation alone is not increased in hyperinnervated motoneurons, it is likely that the increased NE release leads to a larger increase in the MesV EPSP amplitude, compared to controls. The increased MesV EPSP amplitude in hyperinnervated motoneurons in the absence of conditioning stimuli could reflect increased tonic NE release and EPSP facilitation.

According to Rall's cable model of a neuron with a branched dendritic tree, the longer EPSP rise time observed in 6-OHDAtreated animals could result from decreased proximal input (Rall, 1967; Rall et al., 1967), suggesting that fewcr McsV afferents make synapses on the soma and proximal dendrites in the presence of NE sprouting. No significant increase in half-width or duration was observed, consistent with an undisturbed distribution of MesV synapses at more distal sites. As in previous reports, we found that EPSP rise time and amplitude are uncorrelated (Iansek and Redman, 1973; Mendell and Weiner, 1976). This has been explained by assuming that more charge 
is transferred across distal synapses, so that EPSPs are of similar amplitude regardless of synapse location, which results in an absence of spatial weighting of synaptic input. The apparent loss of proximally located MesV synapses on trigeminal motoneurons is in agreement with a recent electron microscopic study that concluded that neonatal 6-OHDA treatment increased the density of NE terminals on trigeminal motoneuron somata, while the density of another morphologically characterized type of terminal is decreased. No change in motoneuron soma size of total synaptic density was observed (Hemmindinger and Moore, 1983).

Hyperpolarizing inhibitory responses to iontophoresed NE have been reported in many CNS arcas, including spinal motoneurons (Phillis et al., 1968; Weight and Salmoiraghi, 1967) and spinal cord explants (Pun et al., 1985), although the specificity of the motoneuron response has been questioned (Engberg et al., 1976). We also sometimes observed early hyperpolarizations after $\mathrm{LL}$ region stimulation and, in hyperinnervated motoneurons, a lower membrane potential. If NE generally increases the efficacy of non-NE synapses, then tonic release could facilitate tonically active inhibitory synapses, producing the observed hyperpolarization and decreased input resistance, while also facilitating the masseteric reflex when primary afferent fibers discharge - the overall effect being to increase the signalto-noise ratio, as suggested by Woodward et al. (1979).

These results parallel an investigation of the sensory trigeminal nucleus in which an increase in noradrenergic inhibition was found following neonatal 6-OHDA treatment (McBride and Sutin, 1984). While NE denervation causes an up-regulation of adrenergic receptors at some synaptic sites, receptor down-regulation does not prevent significant physiological alterations in NE hyperinnervated nuclei.

\section{References}

Araki, T., and T. Otani (1955) Response of single motoneurons to direct stimulation in toad's spinal cord. J. Neurophysiol. 18: 472485.

Astrom, K. E. (1953) On the central course of afferent fibers in the trigeminal, facial, glossopharyngeal, and vagal nerves and their nuclei in the mouse. Acta Physiol. Scand. 29: 209-320.

Bonvallet, M., and E. G. Bobo (1975) Amygdala and masseteric reflex II. Mechanism of the diphasic modifications of the reflex elicited from the "defence reaction area." Role of the spinal trigeminal nucleus (pars oralis). Elcctrocnccphalogr. Clin. Neurophysiol. 39: 341-352.

Chase, M. H., S. H. Chandler, and Y. Nakamura (1980) Intracellular determination of membrane potential of trigeminal motoneurons during sleep and wakefulness. J. Neurophys. 44: 349-358.

Dahlstrom, A., and K. Fuxe (1964) Evidence for the existence of monoamine-containing neurons in the central nervous system. Acta Physiol. Scand. 62, Suppl. 232: 1-55.

Desantis, M., V. Limwongse, and D. Rigamonti (1978) Somatotopy in the trigeminal motor nucleus of the rat: Field potentials recorded in the neuron pool after retrograde transport of horseradish peroxidase. Neurosci. Lett. 10: 95-98.

Engberg, I., J. A. Flatman, and K. Kadzielawa (1976) Lack of specificity of motoneurone responses to microiontophoretically applied phenolic amines. Acta Physiol. Scand. 96: 137-139.

Frank, K., and M. G. F. Fuortes (1956) Stimulation of spinal motoneurons with intracellular electrodes. J. Physiol. (Lond.) 134: 451470.

Frazer, A., M. E. Hess, J. Mendels, B. Gable, E. Kunkel, and A. Bender (1978) Influence of acute and chronic treatment with desmethylimipramine on catecholamine effects in the rat. J. Pharmacol. Exp. Ther. 206: 311-319.

Fung, S. J., and C. D. Barnes (1981) Evidence of facilitatory coerulospinal action in lumbar motoneurons of cats. Brain Res. 216: 299311.

Harden, T. K., R. B. Mailman, R. A. Mueller, and G. R. Breese (1979) Noradrenergic hyperinnervation reduces the density of $\beta$-adrenergic receptors in rat cerebellum. Brain Res. 166: 194-198.
Hemmendinger, L. M., and R. Y. Moore (1983) Synaptic reorganization in rat motor trigeminal nucleus following neonatal 6-hydroxydopamine treatment. Soc. Neurosci. Abstr. 9: 988.

Hoffer, B. J., G. R. Siggins, D. J. Woodward, and F. E. Bloom (1971) Spontaneous discharge of Purkinje neurons after destruction of catecholamine-containing afferents by 6-hydroxydopamine. Brain Res. 30: $425-430$

lansek, R., and S. J. Redman (1973) The amplitude, time course and charge of unitary excitatory post-synaptic potentials evoked in spinal motoneurone dendrites. J. Physiol. (Lond.) 234: 665-688.

Jonsson, G., and H. Hallman (1978) Changes in $\beta$-receptor binding sites in rat brain after neonatal 6 -hydroxydopamine treatment. Neurosci. Lett. 9: 27-32.

Jonsson, G., C. Pycock, K. Fuxe, and C. Sachs (1974) Changes in the development of central noradrenaline neurones following neonatal administration of 6-hydroxydopamine. J. Neurochem. 22: 419-426.

Kalisker, A., C. O. Rutledge, and J. P. Perkins (1973) Effect of nerve degeneration by 6-hydroxydopamine on catecholamine-stimulated adenosine $3^{\prime}, 5^{\prime}$ monophosphate formation in the rat cerebral cortex. Molec. Pharmacol. 9: 619-629.

Katz, B., and S. Thesleff (1957) On the factors which determine the amplitude of the "miniature end-plate potential." J. Physiol. (Lond.) 137: $267-278$

Kidokoro, Y., K. Kubota, S. Shuto, and R. Sumino (1968) Reflex organization of cat masticatory muscles. J. Neurophysiol. 31: 695708.

Kuno, M., and J. T. Miyahara (1969) Analysis of synaptic efficacy in spinal motoneurones from "quantum" aspects. J. Physiol. (Lond.) 201: 479-493.

Levitt, P., and R. Y. Moore (1980) Organization of brainstem noradrenaline hyperinnervation following neonatal 6-hydroxydopamine treatment in rat. Anat. Embryol. 158:133-150.

Llinas, R. (1964) Mechanisms of supraspinal actions upon spinal cord activitics. Differences betwecn reticular and ccrebcllar inhibitory actions upon alpha extensor motoneurons. J. Neurophysiol. 27: $1117-$ 1126.

Madison, D. V., and R. A. Nicoll (1982) Noradrenaline blocks accommodation of pyramidal cell discharge in the hippocampus. Nature 299: 636-638

Matesz, C. (1981) Peripheral and central distribution of fibres of the mesencephalic trigeminal root in the rat. Neurosci. Lett. 27: 13-17.

McBride, R. L., and J. Sutin (1984) Noradrenergic hyperinnervation of the trigeminal sensory nuclei. Brain Res. 324: 211-221.

McCall, R. B., and G. K. Aghajanian (1979) Denervation supersensitivity to serotonin in the facial nucleus. Neuroscience 4: 1501-1510.

Mendell, L. M., and R. Weiner (1976) Analysis of pairs of individual Ia-E.P.S.P.s in single motoneurones. J. Physiol. (Lond.) 255: 81-104.

Moiscs, H. C., D. J. Woodward, B. J. Hoffer, and R. Fredman (1979) Interactions of norepinephrine with Purkinje cell responses to putative amino acid neurotransmitters applied by microiontophoresis. Exp. Neurol. 64: 493-515.

Pellegrino, L. J., A. S. Pellegrino, and A. J. Cushman (1967) A Stereotaxic Atlas of the Rat Brain, Plenum, New York.

Phillis, J. W., A. K. Tebecis, and D. H. York (1968) Depression of spinal motoneurones by noradrenaline, 5-hydroxytryptamine and histamine. Eur. J. Pharmacol. 4: 471-475.

Pun, R. Y. K., K. C. Marshall, W. J. Hendelman, P. B. Guthrie, and P. G. Nelson (1985) Noradrenergic responses of spinal neurons in locus coeruleus-spinal cord co-cultures. J. Neurosci. 5: 181-191.

Rall, W. (1967) Distinguishing theoretical synaptic potentials computed for different soma-dendritic distributions of synaptic input. J. Neurophysiol. 30: 1138-1168.

Rall, W., R. E. Burke, T. G. Smith, P. G. Nelson, and K. Frank (1967) Dendritic location of synapses and possible mechanisms for the monosynaptic EPSP in motoneurons. J. Neurophysiol. 30:11691193.

Reisine, T. (1981) Adaptive changes in catecholamine receptors in the central nervous system. Neuroscience 6: 1471-1502.

Rosenblatt, J. E., C. B. Pert, J. F. Tallman, A. Pert, and W. E. Bunnery (1979) The effect of imipramine and lithium on $\alpha$ and $\beta$ receptor binding in rat brain. Brain Res. 160: 186-191.

Sachs, C., C. Pycock, and G. Jonsson (1974) Altered development of central noradrenaline neurons during ontogeny by 6 -hydroxydopamine. Medical Biol. 52: 55-66. 
Sauerland, E. K., Y. Nakamura, and C. D. Clemente (1967) The role of the lower brainstem in cortically induced inhibition of somatic reflexes in the cat. Brain Res. 6: 164-180.

Schwartz, J. C., J. Costentin, M. P. Martres, P. Protais, and M. Baudry (1978) Modulation of receptor mechanisms in the CNS: Hyper- and hyposcnsitivity to catecholamines. Neuropharmacology 17:665-685.

Sessle, B. J. (1977) Identification of alpha and gamma trigeminal motoneurons and effects of amygdala, cerebellum, and cerebral cortex. Exp. Neurol. 54: 303-322.

Sporn, J. R., T. K. Harden, B. B. Wolfe, and P. B. Molinoff (1976) Beta-adrenergic receptor involvement in 6-hydroxydopamine-induced supersensitivity in rat cerebral cortex. Science 194: 624-626.

Sporn, J. R., B. B. Wolfe, T. K. Harden, and P. B. Molinoff (1977) Supersensitivity in rat cerebral cortex: pre- and postsynaptic effects of 6-hydroxydopamine at noradrenergic synapses. Molec. Pharmacol. 13: 1170-1180.

Strahlendorf, J. C., H. K. Strahlendorf, R. E. Kingsley, J. Gintautas, and C. D. Barnes (1980) Facilitation of the lumbar monosynaptic reflexes by locus coeruleus stimulation. Neuropharmacology 19:225230.

Teyler, T. J., W. Mayhew, C. Chrin, and J. Kane (1982) Neurophysiological field potential analysis by microcomputer. J. Neurosci. Methods 5: 291-303.

VanderMalen, C. P., and G. K. Aghajanian (1980) Intracellular studies showing modulation of facial motoneurone excitability by serotonin. Nature 287: 346-347.

Vornov, J. J., and J. Sutin (1983a) Brainstem projections to the normal and noradrenergically hyperinnervated trigeminal motor nucleus. $\mathrm{J}$. Comp. Neurol. 214: 198-208.

Vornov, J. J., and J. Sutin (1983b) Noradrenergic hyperinnervation alters resting membrane properties and response to synaptic input. Soc. Neurosci. Abstr. 9: 985.

Vornov, J. J., and J. Sutin (1983c) Noradrenergic hyperinnervation enhances facilitation of trigeminal motoneurons. Anat. Rec. 205: 207a.

Wang, R. Y., C. Motigny, and G. K. Aghajanian (1978) Supersensitivity in the amygdala and ventral lateral geniculate in 5,7-hydroxytryptamine pretreated rats. Soc. Neurosci. Abstr. 4: 285.

Waterhouse, B. D., H. C. Moises, and D. J. Woodward (1980) Noradrenergic modulation of somatosensory cortical neuronal responses to iontophoretically applied putative neurotransmitters. Exp. Neurol. 69: 30-49.

Weight, F. F., and G. C. Salmoiraghi (1967) Motoneurone depression by norepinephrine. Nature 213: 1229-1230.

Wolfe, B. B., T. K. Harden, J. R. Sporn, and P. B. Molinoff (1978) Presynaptic modulation of beta-adrenergic receptors in rat cerebral cortex after treatment with antidepressants. J. Pharm. Exp. Therap. 207: 446-457.

Wolfe, B. B., K. P. Minneman, and P. B. Molinoff (1982) Selective increases in the density of cerebellar $\beta 1$-adrenergic receptors. Brain Res. 234: 474-479.

Woodward, D. J., M. C. Moises, B. D. Waterhouse, B. J. Hoffer, and R. Freedman (1979) Modulatory actions of norepinephrine in the central nervous system. Fed. Proc. 38: 2109-2116. 